Historic, archived document

Do not assume content reflects current scientific knowledge, policies, or practices. 



\section{Galloway's New"Planting"Contest}

\section{These RULES}

\section{Must Be Observed}

1. Any person, man, woman or child in with Galloway Bros. Co. may enter this con2. The contest closes Midnight, July 4 th, accepted after this date.

3. The answer with the largest list of words which correctly name objects shown in the this circular wins first prize. Each separate object listed counts as one point in the total score. The answer with the second largest
number of points wins second prize and so on nown for each successive prize.

4. Only objects - as defined by Webster's Unabridged "Dictionary -are acceptable. "tailor" "ears,", "nose," ete. an are parts of an object machines, implements, et.

5. In each case the amount of the prize will be determined according to

6. All objects in the picture are clearly shown and are found in Webster s Unabridge cnce should be written in plural form and will only count as one object. All objects havin

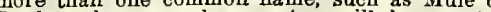
Donkes, house oither syonym will be counte as correct. Obsolete, foreign and slang name and expressions or given names of people are
not permissible. words will be accepted. Flowers and vegethe common names of the varieties shown, for and "Vegetables," varieties such as "Sun-flowisirds" and poultry must be listed by commo names instead of classifying as "Live stock," point against the score of the contestant.

7 . The winning list will be determined by all names of objects submitted by contestants
and "not controled by any predetermined list 8. Only one prize will be awarded in any one houshold, but all members of the hous

9. Write words on only one side of the gheet, using contest blank below to begin with if additional space or sheets are used, write on top of each sheet. Number each word con-
top 10. In the case of ties, for any prize ofgered, the full amount of then

11. In all cases, contestant agrees to
bide by the decisions of the judges in their a warding of prizes.

12. Prizes will be awarded as soon as posgible after the closing date of the contest, at
which time the winning list will be published in special announcement.

\section{Try It--You May Win $\$ 500$}

Who knows? The most surprised folks in the country were some of those winning prizes in the last contest. It all depends on how sharp your eyes are. Anyone can win the $\$ 500$ first prize or any of the other cash prizes. It might as well be you.

Here is a pleasant way to pass the evening and a mighty profitable one too. Everyone in the family can help. And there are enough cash prizes so you don't have to have an absolutely perfect list to win a prize.

\section{Big Cash Prizes}

Winning a prize is just like finding the money and it's just as much fun preparing your list of names, whether you are one of the lucky ones"or not. Remember IT COSTS NOTHING TO ENTER THIS CONTEST. So get busy.

\section{Buy Your Seeds of Galloway Bros. Win the Largest Prize}

Send your order for the seeds you need right away. You cannot beat these Galloway highest quality seeds that grow. Guaranteed seed from Galloway make bumper crops certain. You will buy seeds anyway so why not make your order count for a bigger cash prize by getting your order from Galloway? You'll be buying seeds soon-send your order today, take advantage of the famous Galloway low prices and guaranteed high quality. It will apply in the contest and bring you a larger cash prize.

\section{$\$ 1500$ in Cash-146 Prizes in All--YouCanWin}

CASH PRIZES WILL BE AWARDED AS FOLLOWS

\begin{tabular}{|c|c|c|c|c|c|}
\hline 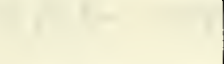 & $\underset{\text { If no order is sent }}{\text { CLASS A }}$ & $\underset{\$ 1.50}{\text { CLASS }} \underset{\text { order }}{B}$ & $\underset{\$ 3.00}{\text { CLASS }} \underset{\text { order }}{C}$ & $\underset{\$ \$ 5.00}{\text { CLASS Order }}$ & $\underset{\$ 10.00 \text { order }}{\text { CLASS }}$ \\
\hline 1st Prize... . . & $\$ 75$ & $\$ 150$ & $\$ 200$ & $\$ 300$ & $\$ 500$ \\
\hline 2nd Prize...... & 50 & 100 & 150 & 200 & 300 \\
\hline$\overline{\text { 3rd Prize....... }}$ & 40 & 75 & 100 & 100 & 200 \\
\hline$\overline{\text { Ath Prize...... }}$ & 30 & 60 & 75 & 85 & 100 \\
\hline 5th Prize...... & 20 & 50 & 50 & 65 & 75 \\
\hline 6th Prize...... & 10 & 30 & 30 & 40 & 50 \\
\hline zth Prize...... & 8 & 20 & 20 & 30 & 35 \\
\hline Sth Prize. . . . . & 6 & 15 & 15 & 20 & 25 \\
\hline 9th P'rize..... & 5 & 10 & 10 & 10 & 15 \\
\hline$\overline{\text { 10th Prize. . . . }}$ & 4 & 5 & 5 & 5 & 10 \\
\hline 11th Prize.... & 3 & 3 & 3 & 3 & 5 \\
\hline 50 Prizes each. & 2 & 2 & 2 & 2 & 2 \\
\hline 85 Prizes each. & $\mathbf{1}$ & 1 & $\mathbf{1}$ & $\mathbf{1}$ & 1 \\
\hline
\end{tabular}




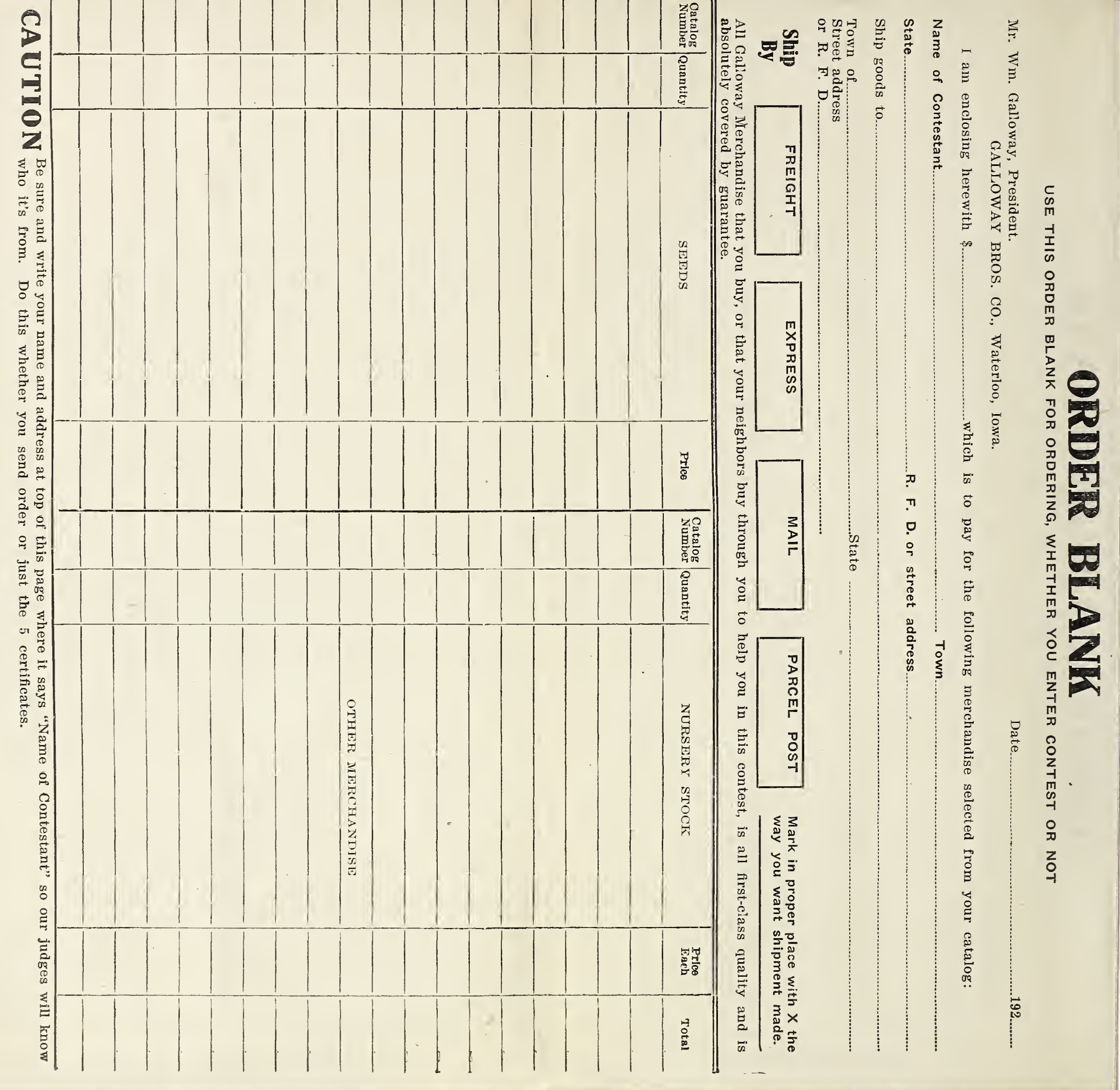




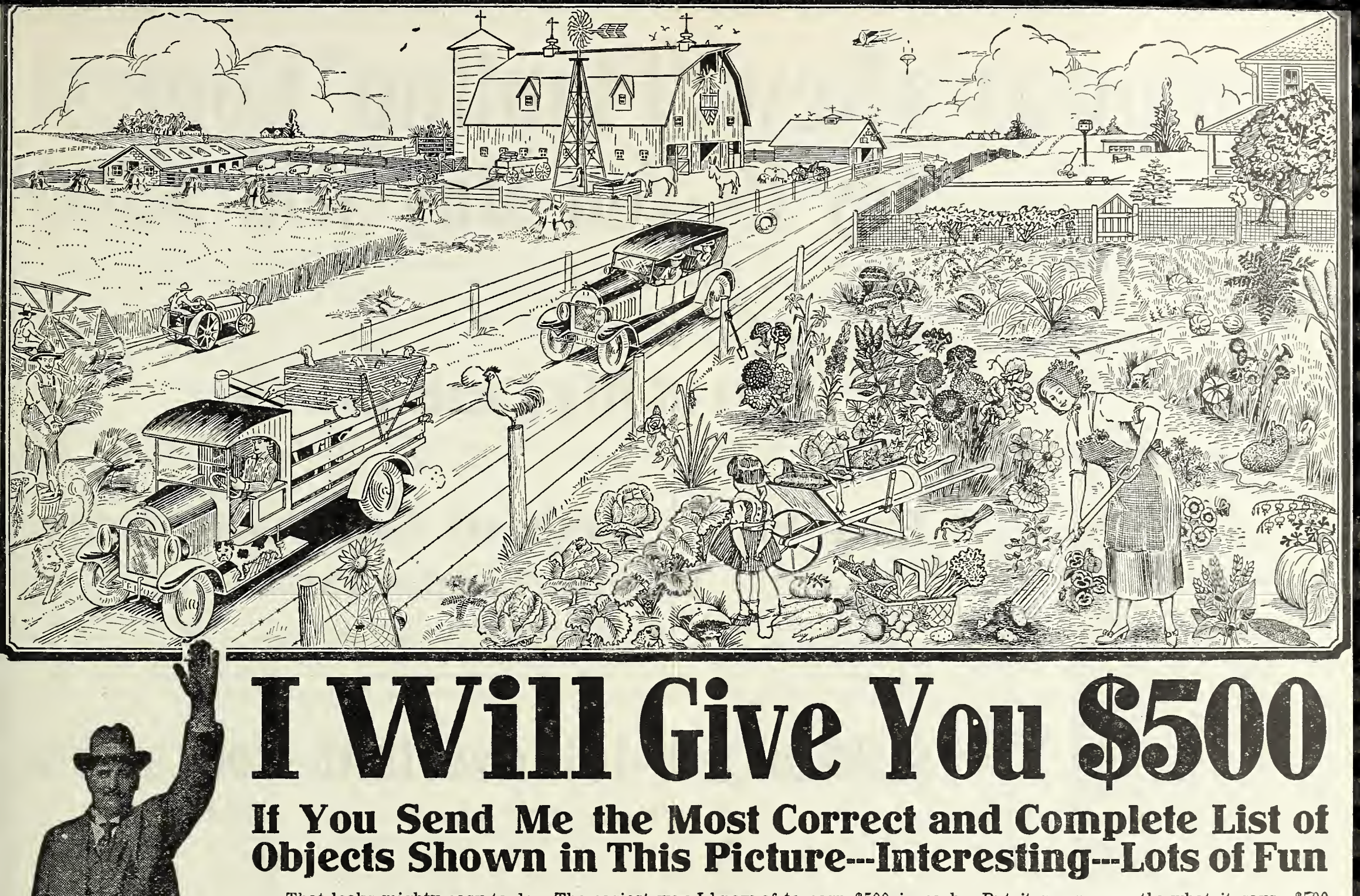




\section{CONTEST ENTRY BLANK}

ORDER BLANK ON OTHER SIDE

GALLOWAY BROS. CO.,

DATE WATERLOO, IOWA

GENTLEMEN :

I am listing below the names of objects shown in your puzzle picture which is a part of this circular. My order sent. 1923 is to apply on this contest in case I win one of the prizes offered. I agree to accept the decision of the judges in awarding prizes on this contest as final.

Name of contestant

Street and Number

R. F. D.

\section{List of Objects Shown in Seed Contest Picture}

